\title{
Automatic feeding and harvesting of juvenile Atlantic cod (Gadus morhua $L$.) in a pond
}

\author{
V. IIESTAD $\dagger$, T. PEDERSEN $\ddagger$, A. FOLKVORD $\S, \AA$. BJORDAL \\ and P. G. KVENSETH§
}

Keywords: Aquaculture, biocontrol, computer control, conditioned behaviour.

Large scale production of juvenile Atlantic cod has been carried out since 1980 in a saltwater pond. A break-through was obtained in 1983 with high survival rates of cod larvae to metamorphosis. In 1985 we made progress in two fields, reduced cannibalism and automatic harvesting. Juvenile cod formed large schools while fed dry pellets in the currents set up by five propellers. An underwater loudspeaker was programmed to give sound pulses just before feeding. During harvesting dry pellets were released inside a fish trap while giving the sound signals the cod juveniles were conditioned to. The cod readily entered the trap and a computer-controlled fish pump transported the fish from the fish trap into a storing tank and grading grids. The trap gradually emptied the pond of fish and more than $80 \%$ or 100000 juvenile cod were captured with the automatic harvesting system.

\section{Introduction}

Large-scale production of juvenile Atlantic cod had a breakthrough in Norway in 1983 (Øiestad et al., 1985). Should these juveniles be used for aquaculture purposes, the production cost per unit would be far below that of salmon. The state-ofthe-art after the 1983 season did not fullfil this precondition, basically due to cannibalism post-metamorphosis and an inefficient capture method of the juveniles.

About 500000 cod larvae survived beyond metamorphosis in 1983, but 3 months later only 75000 juvenile cod had survived to a size larger than $10 \mathrm{~cm}$. Lack of food and large size-differences in the population are considered to be factors increasing the cannibalism rate (Howell, 1984). A possible strategy to reduce cannibalism might be to feed frequently and to disperse the food at the feeding points to reduce the effect of size hierarchy in the population (Fernø and Holm, 1986). Juvenile cod have been observed stemming the stream and feeding on zooplankton coming through the screens in the dam with incoming tide water. An application of this behaviour might be to organize the juvenile cod in currents from propellers in the pond and then feed them dry pellets. An automatic feeding system in combination with the propellers would disperse the dry pellets in the currents as a substitute for the zooplankton.

Received 15 January 1987.

This paper was presented at the IFAC Symposium on Automation and Dataprocessing in Aquaculture, Trondheim, Norway, 18-20 August 1986.

This paper is reprinted with the permission of IFAC.

† Institute of Marine Research, Department of Aquaculture, Bergen, Norway

$\ddagger$ Institute of Fishery Biology, University of Bergen, Norway

$\S$ Austevoll Marine Aquaculture Station, Storebø, Norway

I Institute of Fishery Technology Research, Bergen, Norway 
The traditional harvesting methods in the pond, dipnet and beach seine, have been time- and labour-consuming. Recent experiments with control of fish behaviour by conditioning have given promising results (Balchen, 1985). Manipulation of fish behaviour has enabled researchers to improve yield and harvesting efficiency (Fujiya et al., 1980).

Accordingly also juvenile cod might be conditioned by sound to search for food even inside a fish trap. Such a fish trap could be operated automatically and would gradually empty the pond of cod.

This approach would give reduced labour effort and minimize handling of the fish which are essential components in a cost-efficient production of juvenile cod.

\section{Materials and methods}

\subsection{Location and sampling}

The study was carried out in an enclosed pond (Hyltropollen) in western Norway. The pond has a surface area of $22000 \mathrm{~m}^{2}$, a volume of $60000 \mathrm{~m}^{3}$ and the maximum depth is 5-6 m. Hydrographic monitoring and sampling of phytoplankton, zooplankton and fish larvae were carried out at $0,1,2,3,4$ and $5 \mathrm{~m}$ depth. For more details see Kvenseth and $\emptyset$ iestad (1984) and Folkvord et al. (1985). A brood stock of local Atlantic cod spawned naturally in a plastic pen and the fertilized eggs were collected by a net (Huse and Jensen, 1983).

\subsection{General management}

In mid-March about 2 million cod larvae were transferred from incubators to the pond and released. One month in advance the pond had been treated with rotenon to kill potential fish larva predators. More than half a million cod larvae metamorphosed about 20 April and due to grazing pressure from the fastgrowing cod, the standing crop of zooplankton was brought close to extinction in late April (Fig. 1). Parts of the dam were replaced with metal gratings in early May to permit zooplankton to enter the pond with the tide water.

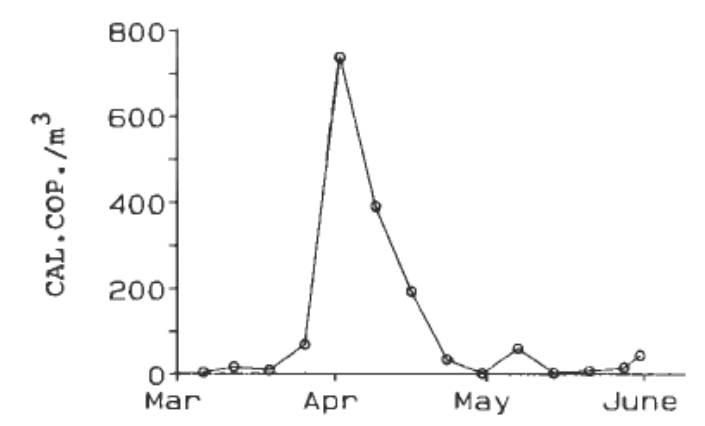

Figure 1. Macro-zooplankton densities at $2 \mathrm{~m}$ depth in the Hyltro pond 1985. Values are numbers $/ \mathrm{m}^{3}$. Onset of dry pellet feeding and start of propellers are indicated.

\subsection{Feeding of juvenile cod in the pond}

Five propellers were placed inside curved pipelines (FLYGT propellers 4350 with $1.3 \mathrm{~kW}$ efficiency and $1400 \mathrm{rpm}$, average flowspeed was approximately $0.2 \mathrm{~m} /$ $\mathrm{sec}$ at $12 \mathrm{~m}$ distance). Dry pellets were supplied from a common automatic feeder, 
and entered at the surface end of the curved pipelines (JEFO automatic feeding system). The pellets did not disintegrate before they were eaten by the cod in the streams (Fig. 2).

The pellets were made of fish meal $(47 \%)$, shrimp meal $(20 \%)$, wheat $(16 \%)$, fat $(9 \%)$, binder $(7 \%)$ and vitamins $(1 \%)$. Only the first two tons of pellets given to the cod contained shrimp meal, as a chemical attractant for cod. The shrimp meal was replaced by fish meal from mid-June. The pellet size used increased gradually from $0.6 \mathrm{~mm}$ in May to $3.5 \mathrm{~mm}$ in August.

The juveniles were fed every $6 \mathrm{~min}$ from 6 May to 30 June and every $10 \mathrm{~min}$ onward. From early July the feeding regime was re-programmed from an $18 \mathrm{~h}$ feeding cycle (from $3 \mathrm{a}$ a.m. to $12 \mathrm{p} . \mathrm{m}$.) in the five propellers, to a 12 a.m. to $3 \mathrm{p} . \mathrm{m}$. feeding cycle at the propellers combined with a 9 a.m. to 12 a.m. feeding at a position close to the fish trap, and in the trap. The total daily ration was gradually increased from $20 \mathrm{~kg}$ in May, $70 \mathrm{~kg}$ in June, $100 \mathrm{~kg}$ in July, but only $60 \mathrm{~kg}$ in August due to harvesting of juveniles (all values are mean for the month). A loudspeaker was programmed to give sound pulses at $150 \mathrm{~Hz}$ from $25 \mathrm{June}$ as it has been shown that cod has maximum autitory sensitivity at $150 \mathrm{~Hz}$ (Chapman and Hawkins, 1973).

Feeding intervals and intensity could be programmed on an IPC (Industrial Programmable Logic Controls). Operation of the fish trap and loudspeaker was controlled in a similar manner by the IPC. The sound started $30 \mathrm{sec}$ before feeding and lasted $60 \mathrm{sec}$ after the pellets entered the propellers.

\subsection{Monitoring of behaviour of juvenile cod}

The behaviour of juvenile cod was studied by underwater television (UTV). By changing the depth and position of the UTV-camera it was possible to study their reaction to the sound used for conditioning and to disturbances from birds, boats

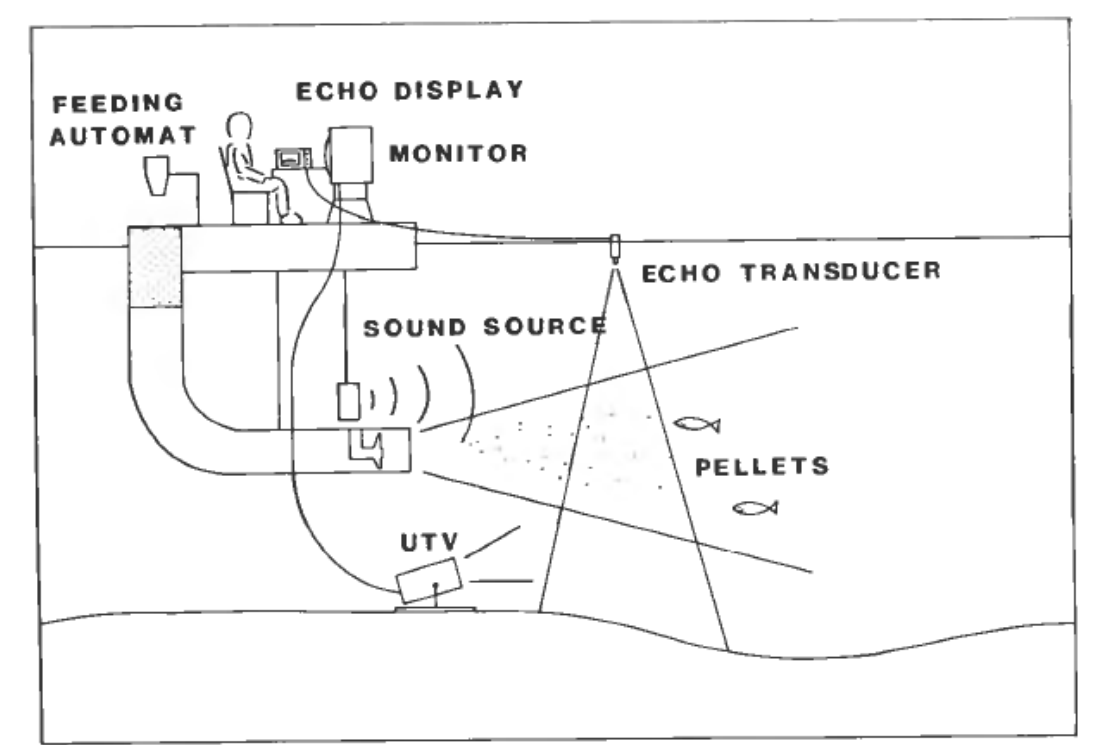

Figure 2. A principal view of the feeding and conditioning system. The pellet was introduced in the stream from a propeller, and in advance of each feeding, a sound signal was given. The behaviour of the juveniles was observed by UTV and echo-equipment. 
etc. (Fig. 2). From mid-June a number of transducers and echosounders were installed to study the vertical and horizontal distribution of juvenile cod in the currents (Fig. 2). General distribution of juvenile cod was studied by surveys in all parts of the pond. The three echosounders used were Skipper model 417 with $200 \mathrm{kHz}$ frequency, connected to five Skipper UT 200 LF transducers with beam angle of $8 \cdot 5^{\circ}$.

\subsection{Harvesting of juvenile cod}

The fish trap was a chamber with a volume of about $2 \mathrm{~m}^{3}$ and with two entrances, each of which could be closed by venetian blinds (Fig. 3). Feeding took place in the chamber, and the other feeding sites were temporarily shut off forcing the juveniles to enter the trap to obtain food. The underwater loudspeaker inside the trap gave $150 \mathrm{~Hz}$ sound signals to attract the cod. The closure of the entrances was followed by pumping out the fish. The juvenile cod were caught in the water stream set up by the fish pump in the bottom of the tank and they were pumped into a storing tank (Fig. 3). Finally the fish entered a high-capacity sorting tank where they were graded in three size-groups and drained to their respective net pens.

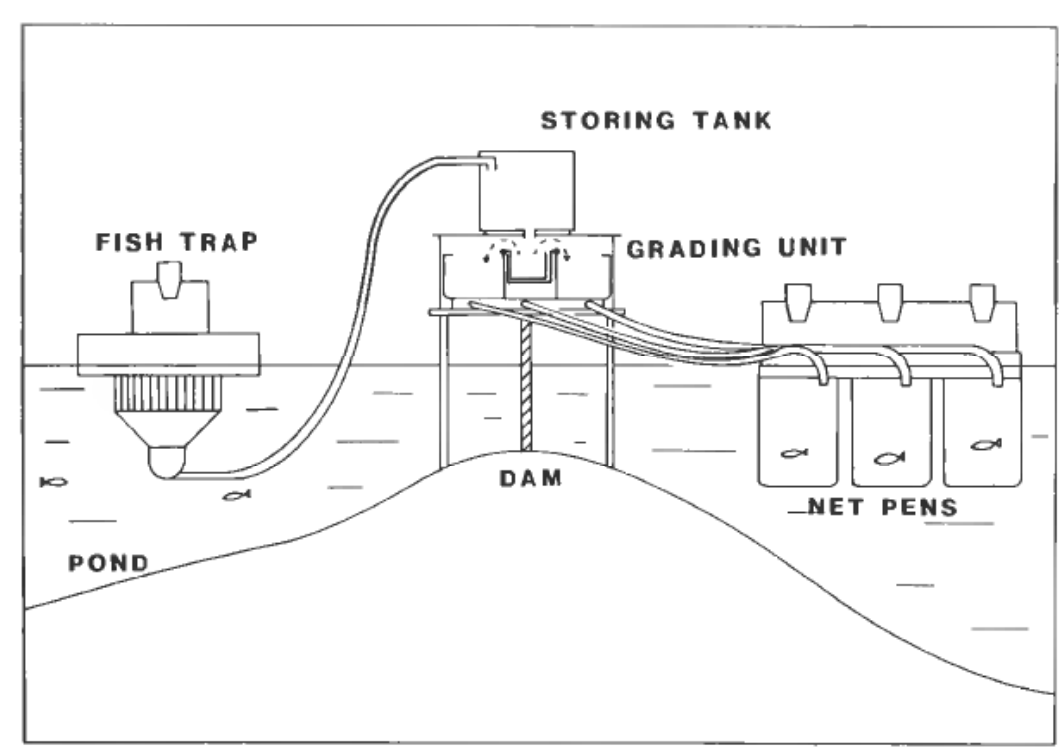

Figure 3. A principal view of the automatic cod harvesting system. The juveniles were attracted to the fish trap by a sound signal in combination with food, the venetian blinds were closed and the juveniles were pumped to a storing tank followed by grading in three size-groups and then drained to separate sea cages. The process was controlled by an IPC.

\section{Results}

From mid-May a large number of juvenile cod were stemming the stream in the incoming tide water grazing on zooplankton. During June the number declined and finally they almost disappeared from the stream. At the same time there was an increasing number of juveniles in the currents set up by the propellers. 


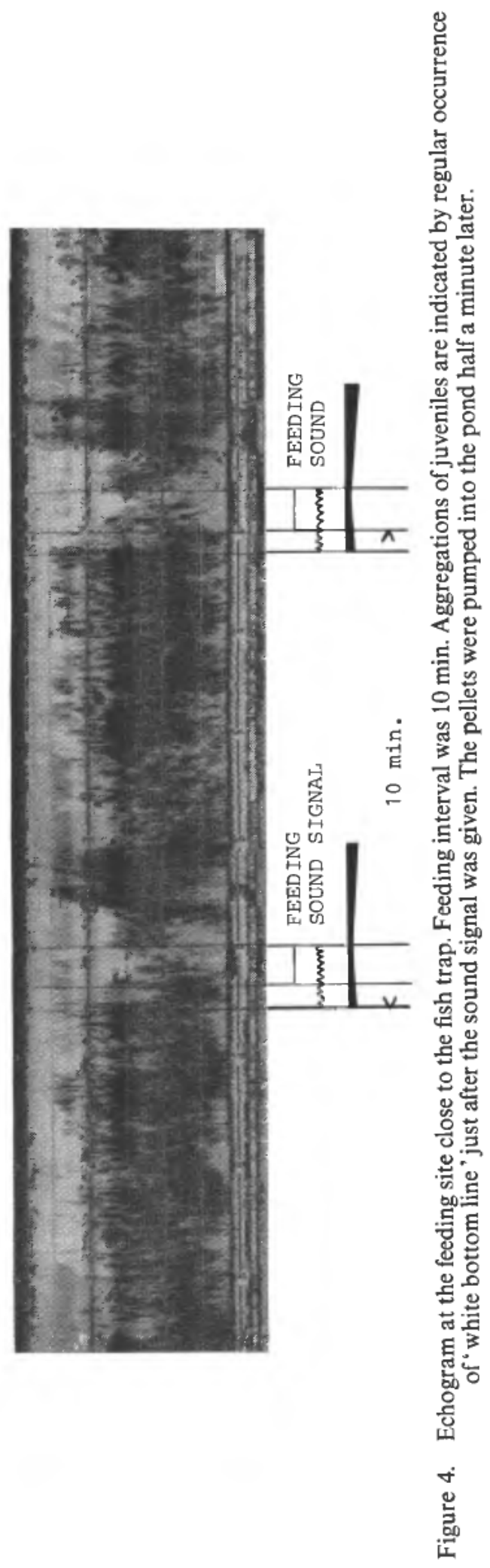


Echo surveys from mid-June showed that during daytime most of the cod were distributed below $2.5 \mathrm{~m}$, while during night time they were distributed throughout the water column. The cod stayed close to the feeding sites and responses to sound signals and feeding could be observed (Fig. 4). Feeding activity was highest at dusk and dawn. During midday they were feeding with lesser appetite and surplus pellets might have dropped to the bottom.

By starving cod for some hours, the reaction towards food was sharply amplified. However, aggressiveness due to starvation was not observed. A number of cod with suspiciously large stomachs were from time to time examined to detect cannibalism, but from early June cannibalism was only observed once among those inspected. The stomachs were at most occasions completely filled with dry pellets and the fraction of zooplankton in the stomachs of the fishes was negligible after mid-June.

During morning feeding the juvenile responded to the sound by swimming in the direction of the feeding point close to the trap. The sound concentrated the fish in that area and when food was released into the trap, large numbers of cod readily swam through the venetian blind entrances. The maximum number of juveniles caught in one operation was about 2000.

At some occasions the juvenile cod stayed too deep and were unwilling to enter the trap. Usually this took place on sunny days. During July and August about 100000 juveniles were caught with the fish trap in this manner. Some thousand remaining cod were removed with dipnets and seines at the end of the harvesting season. These fish were smaller than the ones caught in the trap and had probably not been feeding in the propeller currents. Altogether 120000 juvenile cod were harvested from the pond in 1985 (Fig. 5).

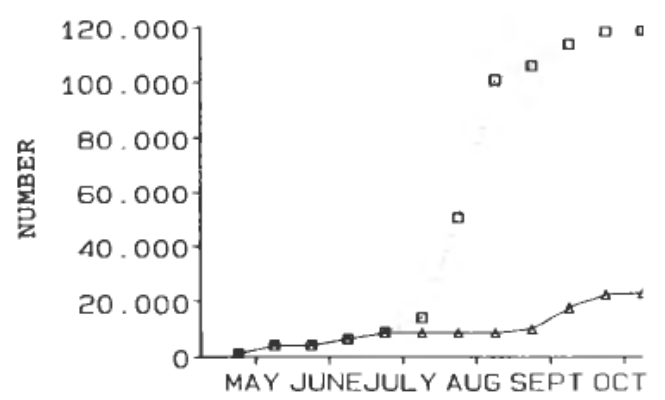

Figure 5. Cumulative catches of juvenile cod in the pond. Lower curve represents juveniles caught with dipnet or seine. The upper curve represents total catch of juveniles with the number exceeding the lower curve representing the catches with the fish trap.

\section{Discussion}

This project was based on two fundamental observations:

juvenile cod stemmed the tidal current to feed on incoming zooplankton and fish can be conditioned by sound to search for food at a particular location.

Could these observations of fish behaviour be used to minimize our problems with juvenile cod production? 
The juvenile cod did change their distribution from one stream to another. This took place when the food supply in the tidal water was insufficient to fill their daily food demand.

Although the propellers were started after collapse of the zooplankton in the pond (Fig. 1), the harvest from the pond went up from 75000 in 1983 to 120000 in 1985. As the survival at metamorphosis was almost the same both years, improved survival of the juveniles in 1985 might have been caused by reduced cannibalism due to the feeding system in artificial currents.

Secondly, although the juveniles were conditioned to search for food in the currents, they were able to change behaviour when food was offered at another position in combination with the sound. The reaction to the sound was strong, and large numbers of juveniles gathered around the trap. Since the juvenile cod were totally dependent upon the pellets for their food supply, we were able to manipulate their behaviour. In 1983 the transition from live to artificial food in the pond took place from day 80 to day 90 (Øiestad et al., 1985), a similar pattern to that observed in 1985.

Some modifications of the system are desirable to operate it more efficiently. The catches were to some extent weather dependent. During days with clear sky and sun the cod tended to stay closer to the bottom. The opening of the trap being about $1 \mathrm{~m}$ below the surface, forced the cod to swim up from the bottom to encounter the pellets. A submersible trap that can be lowered to where the fish are aggregated will perhaps give more uniform catches.

Not all the cod juveniles were caught with the trap. Some were caught with traditional methods before the harvesting system was ready for use (Fig. 5). Towards the end of the harvesting season, traditional methods had to be used to remove some remaining small fish. These smaller individuals had been observed close to the shores where they presumably were feeding on zooplankton and benthic organisms. They grew considerably slower than the individuals eating pellets in the currents from the propellers. Delayed start of the automatic feeding system might partly explain this. The zooplankton population had already been grazed down when the feeding system was put in operation. The size differences generated during this period may have persisted throughout the summer, and the smaller individuals may never have had the chance to compete for pellets with their larger conspecifics (Rosenberg and Haugen, 1982; Fernø and Holm, 1986). It may therefore be essential to have the automatic feeding system running before the zooplankton population collapses.

All major processes in the production of juvenile cod have finally been investigated, and an acceptable solution which can make full scale commercial production of cod possible, is now developed. Further refinements are suggested, and it should be possible to increase both the yield and the efficiency of the described method.

\section{ACKNOWLEDGMENTS}

The authors would like to thank H. Botnen, O. Enger, J. E. Fosseidengen, A. Kristiansen, T. O. Nilsen and J. T. $\emptyset$ vredal for technical assistance. The project was funded by the Norwegian Oil/Fish Fund. 


\section{REFERENCES}

Balchen, J. G. (1985). Recent progress in the control of fish behaviour. Mod. Ident. Cont., 5, 113-121.

Chapman, C. J., and Hawkins, A. D. (1973). A study of hearing in cod, Gadus morhua L. J. Comp. Physiol., 85, 147-167.

Fernø, A., and Holm, M. (1986). Aggression and growth of Atlantic salmon parr. I. Different stocking densities and size groups. FiskDir. Skr. Ser. HavUnders., 18, 113-122.

Folkvord, A., Kvenseth, P. G., Pedersen, T., and Øiestad, V. (1985). Mass production of juvenile Atlantic cod (Gadus morhua L.) in a pond: results and new approaches in 1985. ICES C.M. I985/F:63. 12 pp.

Fujiya, M., SaKaguchi, S., and Fukuhara, O. (1980). Training of fishes applied to ranching red sea bream in Japan. In J. E. Bardach, J. J. Magnuson, R. C. May and J. M. Reinhart (Eds.). Fish behaviour and its use in the capture and culture of fishes. ICLARM Conf. Proc., 5, 200-209.

Howell, B. R. (1984). The intensive rearing of juvenile cod, Gadus morhua L. In E. Dahl, D. S. Danielssen, E. Moksness and P. Solemdal (Eds.), The propagation of cod Gadus morhua L. Flodevigen Rapportser., 1, 657-675.

Huse, I., and JENSEN, P. A. (1983). A simple and inexpensive spawning and egg collection system for fish with pelagic eggs. Aquacult. Eng., 2, 165-172.

Kvenseth, P. G., and ØIESTAD, V. (1984). Large-scale rearing of cod fry in an enclosed pond on the natural food production. In E. Dahl, D. S. Danielssen, E. Moksness and P. Solemdal (Eds.), The propagation of cod Gadus morhua L. Flodevigen Rapportser., 1, 645-655.

RoSEnBERG, A. A., and HAugen, A. S. (1982). Individual growth and size-selective mortality of larval turbot (Scophthalmus maximus) reared in enclosures. Mar. Biol., 72, 73-77.

Øiestad, V., Kvenseth, P. G., and Folkvord, A. (1985). Mass production of Atlantic cod juveniles Gadus morhua in a Norwegian saltwater pond. Trans. Am. Fish. Soc., 114, 590-595.

\section{Appendix}

\begin{tabular}{|c|c|}
\hline Date & Events \\
\hline Dec 1984 & Rotenone treatment of the pond, 1.0 p.p.m. \\
\hline 1985 & \\
\hline $20 \mathrm{Feb}$ & $\begin{array}{l}\text { Rotenone treatment of the pond, } 0.4 \text { p.p.m. } \\
\text { Start of a propeller to mix water masses }\end{array}$ \\
\hline $13 \mathrm{Mar}$ & Closure of the dam \\
\hline 15 Mar & Release of cod larvae $(1800000)$ \\
\hline $20 \mathrm{Apr}$ & $\begin{array}{l}\text { Observed large amounts of post-metamorphosed cod. } \\
\text { Started feeding dry pellets }\end{array}$ \\
\hline 06 May & Start of the propellers in combination with feeding \\
\hline 10 May & Dam partly replaced with gradings \\
\hline 01 Jun & First use of echosounders for distribution survey \\
\hline $23 \mathrm{Jul}$ & Start of harvesting cod juveniles with harvesting unit \\
\hline
\end{tabular}

Table 1. Hyltropond events 1985 